\title{
The Precarious Ecologies of Cosmopolitanism
}

\author{
Marsha Meskimmon
}

\section{Making Worlds After the Fact}

Fleeting, fragile patterns, rendered in dust, gradually covered the floor of an abandoned Georgian farmhouse in Bicker, Lincolnshire, as the artist Catherine Bertola meticulously 'cleaned' the space from dawn to dusk each day for nearly a month in 2006. ${ }^{1}$ Her cleaning ${ }^{2}$ was a drawing in, and out from, dust - a slow, repetitive process of working with the material residue of the past in the space of the present, so that the two worlds collided, after the fact. Their collision was quotidian, rather than dramatic, the traces of one world were re-made in another using the humblest, yet most ubiquitous of materials - dust. The particles that materialised the elaborate, yet tenuous, interconnections between past and present worlds in After the Fact were themselves evocative of a double movement in time. Dust signals both the radical un-making of the world, its movement toward entropy, and the agency of world-making, the material trace left in the wake of human and non-human activities that seek to give shape and meaning to the world.

I want to suggest that there is a compelling connection between the dust that was so central to After the Fact and a provocative statement made by American philosopher Nelson Goodman when he considered from what we might make worlds. As he argued: 'Not from nothing, after all, but from other worlds. Worldmaking as we know it always starts from worlds already on hand; the making is a remaking.' ${ }^{3}$ Goodman's formulation is a useful starting point for thinking through the complexities of worlds and world-making in art as it reminds us that there is no outside to art-making, no privileged beyond from which to represent a world, only the stuff of which the art and the world both comprise. From dust to world, from world to dust, world-making in art is always after the

\footnotetext{
1 Catherine Bertola's site-specific installation, After the Fact was performed as part of the Beacon Art project of 2006, no place, like home, curated by John Plowman across a number of sites in Lincolnshire between 9 September and 10 October.

2 'Cleaning' is literally invoked here-the work was made of dust, soap and polish, using dusters and cleaning cloths as tools. The notion of cleaning as women's work was also recognised by the artists and by a number of critics of the work. See for example, 'Uncovering the Past with Catherine Bertola' Catherine Bertola interviewed by Victoria Redshaw, Opus Trends Blog, posted March 2009, http://trendsblog.co.uk/?p=358

3 Goodman, N. 1978, Ways of Worldmaking, Indianapolis, Hackett, p. 7.
} 
fact, yet never out of time. There is no end to the enterprise of world-making, nor to the potential for material transformation in art-making. Nor does worldmaking in art conform to a unidirectional temporality, a teleological mission or final utopian destination. World-making in this sense is ecological, it describes ongoing, mutable processes and systems of relation that take place between living and non-living things. And, arguably, where art-making becomes worldmaking, materiality becomes crucial to ecology.

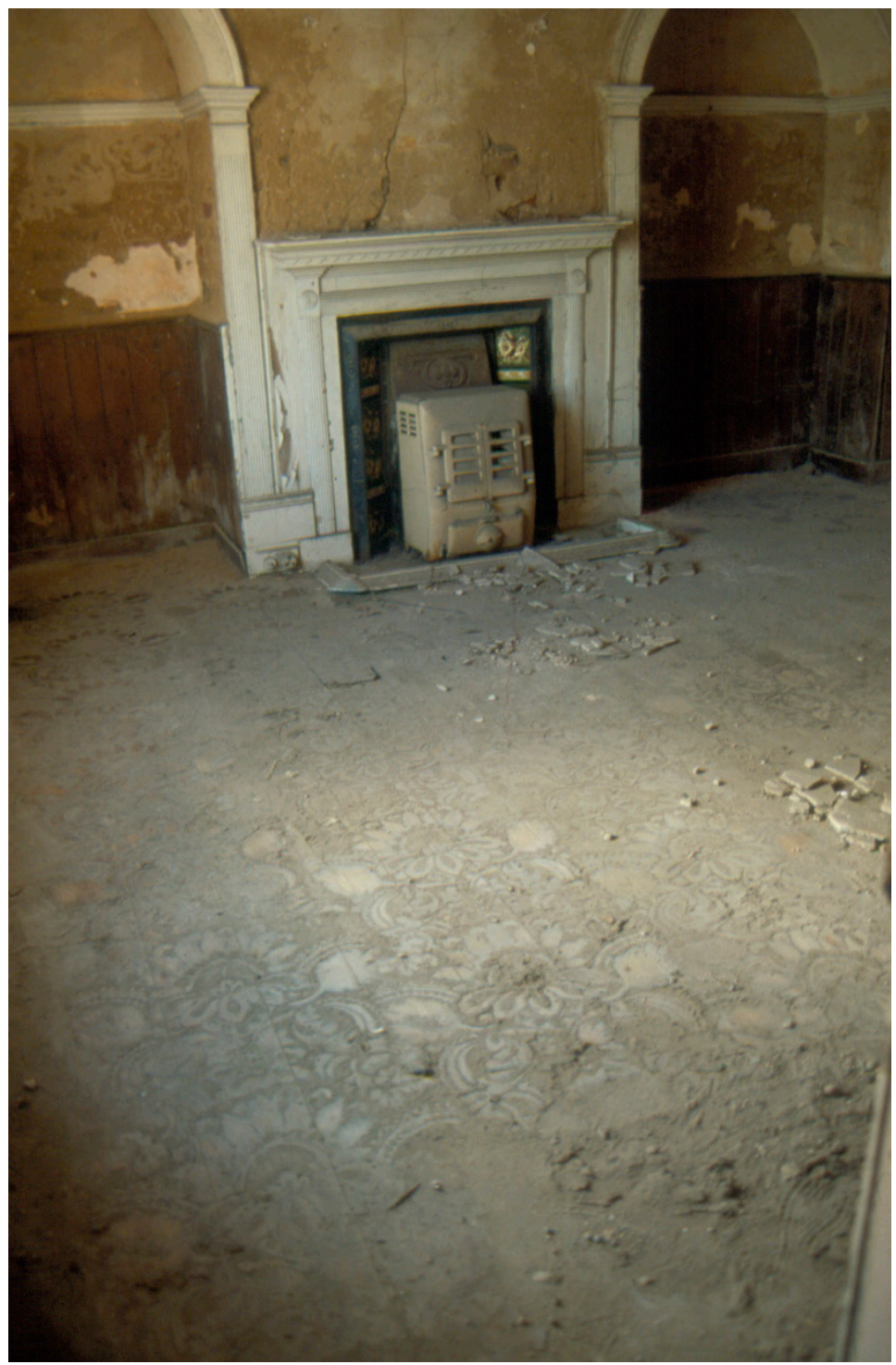

Catherine Bertola, 2006, After the Fact, Found dust and sound. 
Bertola's recurrent labour in making After the Fact was as integral to its meaning as the dust from which it was made. The large and complex patterned dust drawing threatened to decompose, to be un-made, without the continual attention, effort and care of the artist as she 'cleaned' the floor each day. When she departed, dust slowly reclaimed the space leaving only the photographic trace of the work as its legacy. The hours upon hours of Bertola's laborious cleaning never displaced the dust, her excessive work could neither hold back time, nor remove the residual traces of past worlds. The work's production was itself an instance of world-making as re-making, the ecology it sustained for the period of its installation was a perpetual material transformation in and of time. The resultant site-specific drawing did not simply replace the 'past' with the 'present', but brought them together within the same space, in and of the same material, transformed.

Significantly, After the Fact did not illustrate the history of its site, nor did it present an image of a Georgian domestic interior. Rather, it produced a space in which it was possible to (re-)encounter, imaginatively, the curves and arabesques that once adorned the papered walls of the Georgian farmhouse, now gone to dust. Re-animated through patterns traced in that self-same dust, their tenuous lines were drawn out across the wooden floor. The space was thus articulated as a locus for memory and imagination that collapsed time and folded worlds into one another through their re-making as art. In this re-making, facture and material were intimately intertwined and mutually constitutive. The repetitive activity of drawing in dust, allowed the emergence of the dust as drawing. Returning to Goodman: 'The many stuffs - matter, energy, waves, phenomenathat worlds are made of are made along with the worlds.'

If we are able to describe the agency of Bertola's work as an ecology, as a dynamic and sustainable system of relations between subjects, objects and their environment, we must also acknowledge the fragile, ephemeral nature of this ecology. After the Fact was a precarious ecology, a world re-made in art that risked its un-making at every turn. Dust is unsettling sediment; the slightest touch disturbs it, yet its presence is pervasive. The dust drawing at the centre of the installation was precarious; despite its complexity and the repetitive activity of its making, it was fragile and ephemeral, subject to the vicissitudes of movement in its vicinity and to reclamation by the accumulation of new layers of dust over time. It required human maintenance, continual acts of re-making, to remain in situ. After the Fact demonstrates viscerally, in the affective force of its materiality, the fact that even the most elaborate and carefully-composed world may be fleeting and fragile. 
I want to suggest, however, that the precarious ecology configured by After the Fact is more nuanced than these direct references to its ephemeral materials and tenuous facture convey. While the precarious does signal fragility, ephemerality, uncertainty and risk, its etymology further connects it with prayer or entreaty. That which is precarious is dependent upon the will or favour of another; it is obtainable through earnest request or negotiation. Arguably, After the Fact could only be produced by working with the dust, rather than upon or against it; the work was effected through an active negotiation with the parameters of the space and its material constraints. The repetitive cleansing traced the lines and patterns of the dust in concert with its own textures, forms and proclivities. The sound derived from the repeated actions of the artist in making the work were recorded and played back into the space, producing a sonic equivalent to its gestural notation. Whilst not a space of prayer in any formal religious sense, the recurrent movements of the artist, accompanied by the rhythmic aurality of the recording in the space, eloquently evoked the meditative qualities of introspective reflection that commonly attend quiet engagement with repetitious manual tasks.

Perhaps not surprisingly, entreaty shares a common root (trahere) with trace; to entreat is to draw down favour. In drawing out the resonances between the particles and the floor, the times past and present that inhered to the interstitial fabric of the dust yielded themselves to the making of the work through the communion between the body of the maker and the world that was being made. In After the Fact, drawing became a form of entreaty, a precarious act of engaged world-making in which subjects and objects were mutually configured as they were drawn forth, in dust, gesture and breath.

The mercurial materiality and manufacture of After the Fact articulated a precarious ecology in an abandoned farmhouse for a month in 2006 and then was gone. Our engagement with the work now, therefore, must always be 'after the fact', our invocation of its affective force summoned through careful and attentive description of what once was made in dust, that has now gone to dust. We cannot experience it again, nor can we inspire others to make the pilgrimage to the work to experience it themselves. However, dust drawings have a history within European modernism, ${ }^{5}$ a history of material transformation through photography that complicates their precarious existence as worlds made in art. In 1920, Marcel Duchamp's Large Glass, which had lain for some years in his studio, undisturbed, collecting dust, became the subject of his interest again, and that of his friend and fellow artist, Man Ray. In what is now acknowledged as a collaborative work, the piece was transformed through photography and re-named: Dust Breeding (Large Glass with Dust Notes), 1920.

5 Information on Bertola's dust work usually notes Duchamp and Man Ray. 


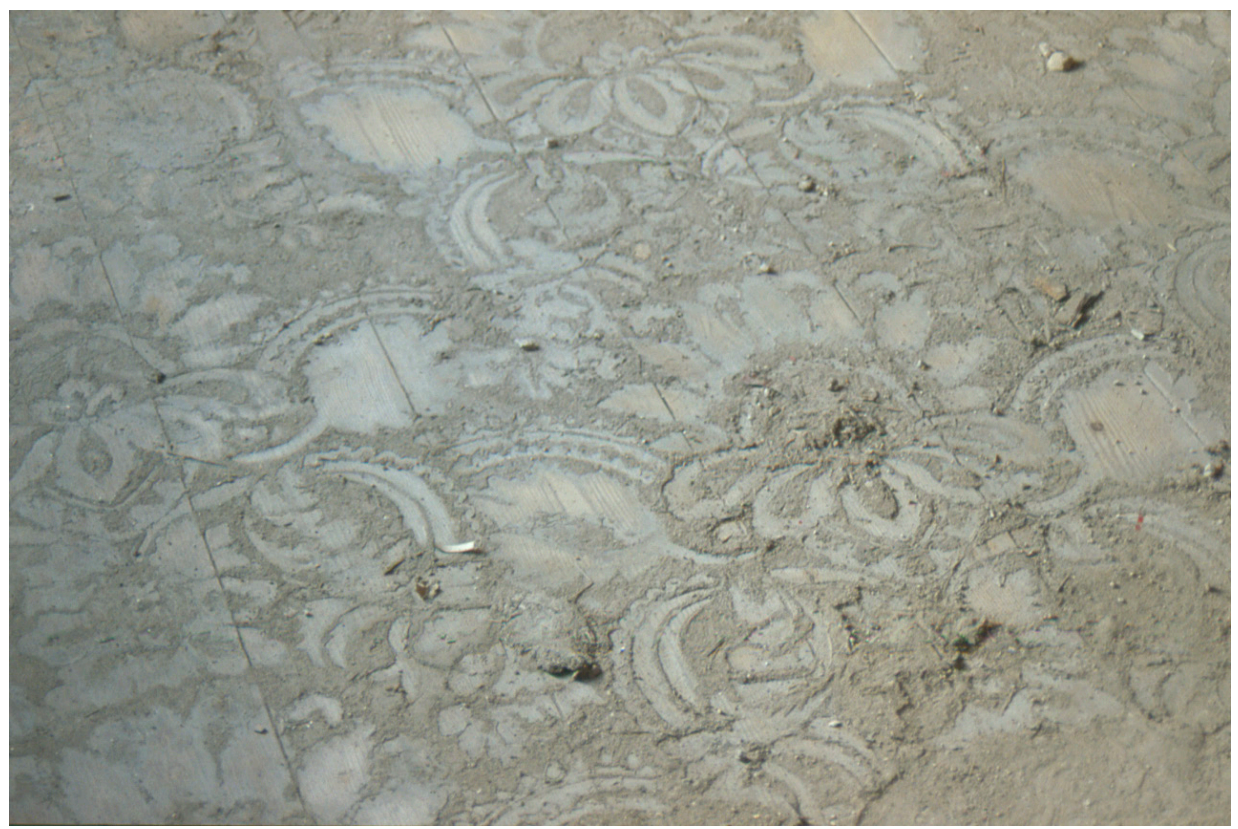

Catherine Bertola, 2006, After the Fact (detail), Found dust and sound.

Courtesy the artist, Workplace Gallery and Galerie M+R Fricke

Like Dust Breeding, I want to argue strongly that After the Fact is not simply a past work, documented in photographs, but a work that has a vital photographic component within its larger and more complex configuration, and that this component adds an important dimension to the dynamics of the piece. In After the Fact, the photographic images of the dust drawing in situ reiterate the complex temporality of the work and render its extraordinary physical presence palpable through the visual focus of the lens. The photograph allows the viewer to grasp the space and the fragile drawing on its floor in one, immediate, look; its transformation of dust traced through light into indexical image adds to the visceral experience of ephemerality in the work by capturing a single moment and holding it stilled.

The photographs of After the Fact are haptic-experienced as tactile through the visual - and they engage us bodily in a work that we may never see 'in the flesh'. In this sense, they participate in what Olivier Asselin, Johanne Lamoureux and Christine Ross have called 'precarious visuality', a bodily form of vision that locates the subject within the dynamic aesthetics of the work, rather than as its distanced or disinterested observer. ${ }^{6}$ The multi-layered affective registers

6 Asselin, O., Lamoureux, J. and Ross C. (eds), 2008, Precarious Visualities: New Perspectives on Identification in Contemporary Art and Visual Culture, Montreal, McGill-Queen's University Press. 
through which the work operates are thus not lost in the photograph, but redoubled. The precarious ecology of the work can be conveyed, after the fact, through the agency of the photograph.

I want also to suggest that one of the most significant qualities of the photographic trace of Bertola's site-specific dust drawing is its capacity to make visible the extraordinary within the ordinary. The photographs are nearly monochrome, the space they image is non-descript, yet from within this quotidian visual locus emerges an elaborate figure, both two and three-dimensional, formed from light, shade, mass and volume, yet tenuous in its presence. It is hard to grasp, it compels us to look, to make it out. It might be called wondrous in its ability to make us regard again, that which we would otherwise simply overlook. ${ }^{7}$

Indeed, our engagement with this work is premised upon many of the perceptual, cognitive and affective states that have, historically, been attributed to 'wonder' - the rupture of the familiar by the appearance of the unfamiliar; a visceral, vertiginous and immediate response compelling an attitude of contemplative enquiry; a temporal suspension characterised by close attention to specific objects. Wonder is not the sublime and After the Fact does not overawe or overwhelm us. Its extraordinary qualities of elaboration and intricacy are a delicate surprise in the space, an unusual encounter within the realm of the familiar that brings us up against the limits of our recognition but offers no threat. It compels our enquiry to become embodied and engaged: What is this? How has it come to be here? What do I make of it? Pausing, lingering and taking pleasure in our encounter with the unfamiliar, we participate in the wondrous, precarious ecologies offered by world-making in art.

In his exploration of the significance of wonder to creative and intellectual enquiry, literary historian Philip Fisher has argued that:

In locating the extraordinary back within the ordinary, explanation breaks open the fabric of the ordinary itself and changes it forever, both for thought and for perception.... The ordinary is not just the dictionary of things we are used to; it is also relations among them.... including contiguity, scale and genres of experience. ${ }^{8}$

World-making is not of necessity dramatic, but it is, potentially, wondrous. We make worlds everywhere and always as we go about our daily rounds, we inhabit worlds that were made before our time and we make worlds that will exceed our own existence. The profundity of such domestic world-making is

7 Lorraine Daston and Katharine Park, in their pivotal 1998 publication on wonder, Wonders and the Order of Nature 1150-1750 (New York, Zone Books), note that regarding the same things anew is frequently a key feature of wonder as a 'sensibility', p. 18.

8 Fisher, P. 1998, Wonder, the Rainbow and the Aesthetics of Rare Experiences, Cambridge, MA, Harvard University Press, p. 100. 
inscribed in the quotidian, and yet, the extraordinary is easily overlooked or disregarded when it resides within the everyday. As Fisher suggests, however, experiencing wonder in the face of the rupture of the extraordinary within the ordinary changes our relationship to the world forever.

Arguably, it is not simply a fortuitous coincidence that links the precarious with the wondrous in this particular work, but rather a more complex interweaving between the affective force of wonder and the materialisation of precarious ecologies in contemporary art. Wonder marks the boundaries of the known and recognised, the limits of the ever same. Moving beyond those limits is a precarious enterprise, risky and, as I will argue, dependent upon other subjects and objects in the world. Wonder is not the only affective play of the precarious that can be engendered by contemporary art, but it is an especially significant state in relation to the interpellation of subjects and agencies in world-making, where the work of world-making is premised upon our interconnections with others and our openness to difference and where world-making changes our relationship to the ordinary forever. As I will draw out in what remains of this essay, it is in this sense that the precarious ecologies of cosmopolitan worldmaking are so often wondrous.

\section{Tethering Time}

In 2001, Australian artist Joan Brassil (1919-2005) installed a large-scale sound sculpture in the grounds of the Campbelltown Arts Centre in the suburbs of Sydney. Entitled A Tether of Time, Brassil's installation enfolds the macro within the micro, taking an oblique view through one particular space, of the many worlds that surround us, unobserved and unnoticed. Exploring the dynamics of this work enables further connections between the precarious and the wondrous to emerge in the world-making agency of art.

A Tether of Time consists of three main elements, roughly configured in the shape of a ' $\mathrm{T}$ '. The 'downstroke' is inscribed by a slim flow of water over terraced steps, running some five metres along the length of the ground. This flow is neither like a natural river stream, nor a traditional fountain, but more like a miniature industrial canal or a modern interpretation of the channeled water in a Moorish garden. The 'cross-stroke' is marked by the most striking feature of the installation: five stainless steel tuning forks, strung with steel wire to produce a wind-harp over eight metres high. Each 'fork' has two smooth, soft-wood panels attached to its base which stand in amidst stone slabs carved with poetic lines referring to the histories of the site, from Aboriginal origins to contact and the later development of a large suburb. 


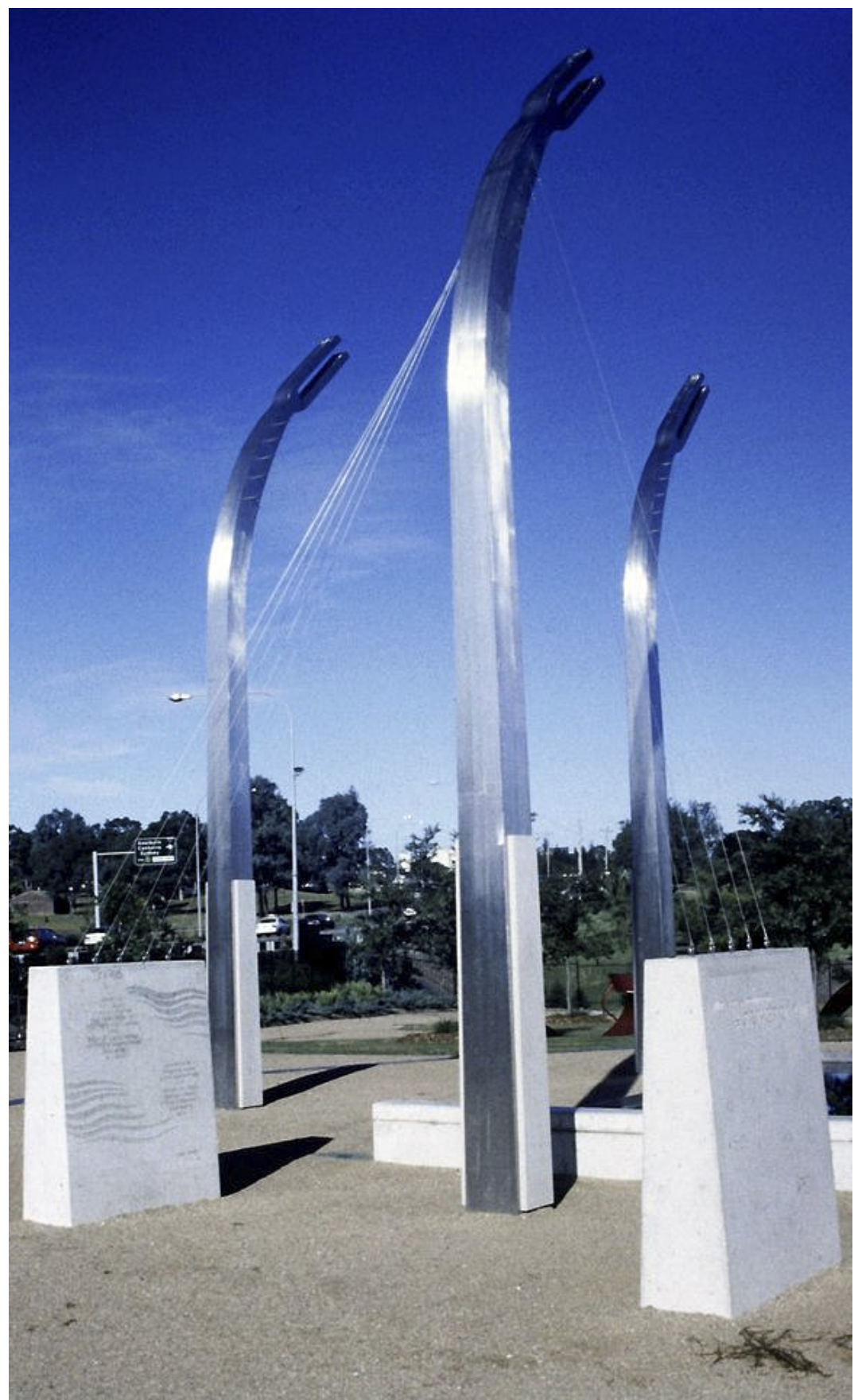

Joan Brassil, 2000-2001, A Tether of Time, Campbelltown Arts Centre Collection, purchased with assistance from the Australia Council 2001, Stainless steel, steel, wire, concrete, jarrah. 
A Tether of Time is typical of Brassil's installation practice more generally, a practice characterised by a poetic use of industrial and technological materials and a meticulous attention to the details of site and meaning. However, the scale of the work, its permanence and its material and structural affinities with the built environment, set it apart from many of the more fragile and tenuous works that mark Brassil's practice. Significantly, however, I want to argue in what follows that the work's substantial physical presence neither negates the precariousness of its world-making, nor the wonder it is capable of engendering.

While the precarious is commonly associated with the fleeting and ephemeral, it can also suggest lingering on the very brink of change - in the terms of the present discussion, the precarious can describe the event of ecological balance, when mutable elements are poised in harmonic connection. A Tether of Time is not so much a free-standing sculpture, as one such 'event', a play conducted between the work's varied physical components as they delineate the space of the sculpture garden and direct spectators' viewpoints and movements within it. Its various shifts of scale and material are seemingly incompatible: the work is solid and fluid, it is massive and delicate, it is an object, an image, a space and a temporal event at once.

The balance of opposing forces in the work sets up a precarious ecology and surprises us with the extraordinary, tethered to the banal, time and again. Driving past the gallery and sculpture garden on one of the suburb's ubiquitous small highways, littered with commercial premises, traffic signs, street lights, telephone and power poles strung with cables, we spot a glistening wind-harp by the side of the road. ${ }^{9}$ And yet, this harp is not at all unlike the street lights and telephone poles themselves - a fact which strikes one all the more powerfully from within the garden where the concrete and steel forms resonate with the oftoverlooked 'view' of commercial suburbia beyond. The installation's contours, materials and setting actually connect the sculpture garden with the surrounding suburban landscape rather than maintaining its isolation as a 'refuge' from what is commonly conceived as an unappealing, disorganised sprawl. A Tether of Time intervenes in Campbelltown's sculpture garden, rather than simply being set in it, and, in so doing, renders the everyday extraordinary. In addition, the work performs the space as a system of relations between subjects and objects within multiple worlds - the sculpture garden, the surrounding suburbs, the cosmos - it is an ecology. More strongly, I would suggest that the work entreats us to take an active role in re-making the world in this otherwise ordinary space; and if we answer this entreaty and engage with the work, we can partake of its precarious wonders.

9 When I visited the site in February 2002, I noticed this myself and Joan Brassil confirmed that she had hoped the wind-harp would surprise drivers - shake them into an awareness of their surroundings. 
In this sense, it is significant that $A$ Tether of Time is a sound sculpture as well as a visual and material intervention into the space. The wind harps capture the movement of the air, making gentle calls, while the flowing water lightly babbles. However, the most fascinating and compelling sounds produced by the work cannot be heard just by walking past it, or by standing in the garden. To hear the unheard, it is necessary to press your ear against the wood at the base of the tuning forks, 'hugging' the poles and feeling their smooth, soft texture on your face. Standing in this way, the sound is magnificent; the slightest tremor of air, the resonance of the earth and the vibrations caused by the buildings and cables in Campbelltown are transformed into beautiful, vibrant song. By physically connecting with the work, the inaudible sounds of the world around you become audible - the virtual breaks into the temporal flow of the everyday in an aesthetic re-making of both the space and the subject who hears/imagines anew. Just as the seamlessness of daily experience is disrupted by the sight of a wind harp by the side of the road, these heterogeneous sounds interrupt our dulled continuity by bringing us to our senses and connecting us to change and opening us to difference.

In $A$ Tether of Time, the extraordinary breaks into the ordinary through a critical shift in the attention of participant-observers, and I use the term 'participant' at this point most deliberately. A Tether of Time is not a work 'in-itself', an object offering itself to the distanced gaze of an onlooker. Rather, it requires the multi-sensory participation of subjects engaging with the work as a process of making connections across difference, to have any effect. The subject is here interpellated through an affective register as a perceptual instrument, captivated in wondrous arrest at the experience of their momentary connection to the cosmos. This enhanced mode of attention reveals the hidden, the unseen and unheard worlds that surround us; we are enworlded and world-making at once. Connected bodily to the random resonances of the multiple worlds we inhabit simultaneously, we become aware of the precariousness of our enworldment and how much threatens to disappear, overlooked, or pass away, unheard..$^{10}$

Activating the precarious links between visual, spatial and aural forms of perception at the point of wonder, A Tether of Time facilitates our potential to inhabit spaces differently. Studies in the physiology of music are instructive here: it is impossible to 'hear' a continual monotone until it is disrupted by a variant sound, because 'hearing' is constituted at once by the physical perception of

10 Art historian Anna Dezeuze, in an abstract for the (as yet unpublished) monograph, 'The "Almost Nothing": Precariousness in Art since the 1960s', notes the possibility of not noticing some particularly precarious artworks. Dezeuze developed this concept from her argument in "The "Do-it-Yourself" Artwork: Participation from Fluxus to New Media', Manchester, Manchester University Press (2010). 
vibration and the cognitive processing of the phenomenon as 'sound' which occurs in differentiation. ${ }^{11}$ 'Hearing' is constituted through attending to, and acknowledging, difference, as much as in any physical activity in the ear.

When we hear the unheard in contact with the tuning forks of Brassil's installation, we are not only having new tonal ranges made available to our bodies through technological instruments, we are becoming aware of the simultaneity of our sensory perception and cognitive processing through the strategic production of a shift in our attention. We are made aware of our embodiment, and through this, our situation within worlds, and the knowledges, narratives and contexts these entail. Like After the Fact, A Tether of Time's world-making is re-making, there is no beyond or outside from which to construct another, different or new, world; the new and the different emerge from past and present worlds, re-made, re-seen, re-heard. World-making in art that acknowledges our embeddedness, our embodied 'worldliness', articulates difference through, rather than beyond, the everyday.

These thoughts have some purchase in thinking through the connections between contemporary art and world-making in a global economy, for those of us who are committed to exploring the possibilities of engendering crosscultural dialogues in and through difference, rather than conceding to a unified, cultural hegemony. What I have termed in this text 'the precarious ecologies of cosmopolitanism' are the sustainable, yet evolving, systems of relation that engender a generous intersubjectivity and an openness to difference. These ecologies are risky, subject to change, premised upon negotiation with others and, I would argue, absolutely critical to an ethical way of inhabiting a global world-to engendering a cosmopolitan imagination. ${ }^{12} \mathrm{I}$ am suggesting that world-making in art is one of the ways in which we might instantiate the wondrous and precarious ecologies that enable us to glimpse the potential of the cosmopolitan imagination to 'open the fabric of the ordinary and change it forever'.

The change in the fabric of the ordinary evoked though such precarious ecologies might better be understood as an exchange, or an encounter, between worlds and

\footnotetext{
11 Roederer, J. G. 1995, The Physics and Psychophysics of Music: An Introduction, [third edn], New York, Springer-Verlag, pp. 3-6.

12 In Contemporary Art and the Cosmopolitan Imagination, London, Routledge (2010), I developed the idea of 'imagination', specifically, but would note the work of Papastergiadis N. 2012, Cosmopolitanism and Culture, Oxford, Polity, in developing the notion of a cosmopolitan 'imaginary'. The latter is an especially good way of bringing the cosmopolitan project into play through the notion of the cultural imaginary, which I would affirm. I have used 'imagination' so to link the idea more specifically to the work, for example, of philosophers Moira Gatens and Genevieve Lloyd, who have argued for the significance of imagination and imagining in the construction of a generous, responsible and intercorporeal subject. See Gatens, M., and Lloyd, G. 1999, Collective Imaginings: Spinoza Past and Present, London, Routledge. I would also note that despite our different emphases, Papastergiadis and I are very much aligned in our thinking about the importance of contemporary art to a cosmopolitan project.
} 
subjects, both of whom are re-made in their meeting. Once we have encountered the drawing traced in dust, After the Fact, we cannot simply overlook the Lincolnshire site as derelict and unworthy of our attention. Bertola's worldmaking re-makes the space and the subjects who engage with it; worlds and subjects are mutually reconstituted in the agency of the artwork. Tethering the temporality of the cosmos to the quotidian, A Tether of Time leaves its trace on those who participate, bodily, in the event it unfolds. The macro opens within the micro and is materialised through the perceptual cognition of the subject; subjects, objects, space and time are mutually re-made.

In a telling passage concerning the political dimensions of globalisation and transnational cultural exchange, Rob Wilson argued that:

at best, globalization is generating new forms of reflexivity, altered terms of citizenship, amplified melanges and ties to transnational culture, and thus provoking an aesthetic of openness toward otherness that is not just the chance for commodification, spectatorship, and colonization. ${ }^{13}$

Wilson's 'aesthetic of openness' is significant. The aesthetic dimension formed part of what he termed the 'new cosmopolitanism', a cosmopolitanism that could, potentially, meet some of the political, ethical and juridical challenges of globalisation. This is not simply a reconstitution of the nineteenth-century European ideal of cosmopolitanism, which tends to privilege an elite form of world-travel through the consumption of high culture mixed with an exciting dash of 'exotica' from the 'rest' of the world. Rather, the cosmopolitanism being explored and developed by Wilson and other scholars, such as Kwame Anthony Appiah, Seyla Benhabib and Mica Nava, ${ }^{14}$ is cognisant of the significant contribution of feminist and postcolonial debates to the framing of 'world citisenship' beyond a masculine-normative, Eurocentric project. Indeed, the work that has emerged in the past decade on cosmopolitanism in the social sciences and humanities is more commonly premised on making connections with others in the world across and through difference, whether those are cultural, sexual, national, ethnic and/or differences of class and economic status. These cosmopolitanisms are situated perspectives on the possibilities of dialogue and community building which acknowledge the complexities of the intertwining

13 Wilson, R. 1998, 'A New Cosmopolitanism is in the Air', in P. Cheah and B. Robbins (eds), Cosmopolitics: Thinking and Feeling Beyond the Nation, Minnesota, University of Minnesota Press, pp. 351-61, 355. Wilson's own background is in literature with specialist interest in the American Pacific.

14 See, Appiah, K. A. 2006, Cosmopolitanism: Ethics in a World of Strangers, New York, W. W. Norton; Benhabib S. et al., 2006, 'Another Cosmopolitanism: Hospitality, Sovereignty, and Democratic Iterations', in R. Post (ed.), Oxford, Oxford University Press; and Nava, M. 2007, Visceral Cosmopolitanism: Gender, Culture and the Normalisation of Difference, Oxford, Berg. 
of the local within the global. And, as I have argued at greater length elsewhere, these are cosmopolitanisms that have a significant relationship to the fields of aesthetics and art-making. ${ }^{15}$

In exploring the specific idea of the precarious ecologies of cosmopolitanism articulated by contemporary art practices as world-making activities, and in connecting these with the affective state of wonder, I am here drawing upon the broad links between aesthetics, art and the embodied, enworlded cosmopolitanisms described very briefly above, but also extending these ideas in new ways. I want to suggest that particular ways of materialising our corporeal and affective exchanges with other subjects and objects in aesthetic world-(re) making activities, have precise ramifications for the development of an ethical cosmopolitan subjectivity and the politics of imagination.

There are three dimensions to these connections that are of particular significance here: the intrinsic links between elite and non-elite experiences and conceptions of precarity, ${ }^{16}$ the non-teleological and non-representational status of a precarious ecology in art, and the compelling generosity of wonder within imagination. In recent years, some political theorists have suggested that the transnational labour markets of the global economy have shifted such that we now no longer have a mass proletariat, but a mass precariat, a pool of lowpaid, insecurely employed and highly mobile, global workers and transnational economic migrants. ${ }^{17}$ The precarious state in which this global non-elite labour force exist is widely condemned and, I would argue, rarely connected to the increasing insecurity and mobility of an elite global labour force in the form of, for example, international artists, architects, designers, academics, corporate executives, IT specialists and other high-level 'consultants'.

These two groups of 'cosmopolitans' share their 'precarious' experience of globalisation, but clearly are divided by their economic status and the power differentials this brings. Finding ways to articulate both the high and low status experiences of the precarious nature of production within a global economy sets out the possibility of a fuller and richer cosmopolitan conversation that brings together elite and non-elite cultural exchange. I want to suggest that this is one of the possibilities of art-making as world-making, though I am not suggesting here that the international contemporary art-world is universally accessible. What I am suggesting is that art as world-making permits a space

\footnotetext{
15 Meskimmon, M. 2010, Contemporary Art and the Cosmopolitan Imagination, London, Routledge.

16 Judith Butler makes a similar point concerning the political valence of the term 'precarity' which is more precisely demonstrative of economic, social and cultural disempowerment (non-elite status) than 'precariousness'. See Butler, J. 2009, Frames of War: When is Life Grievable? London, Verso, pp. 25-32. In addition, I would argue that it is not just a coincidence that wonder has also had 'elite' and 'non-elite' versions over its long history. See Marr, A. 2006, 'Introduction', in R. J. W. Evans and A. Marr (eds), Curiosity and Wonder from the Renaissance to the Enlightenment, London, Ashgate, pp. 1-20, 15-16.

17 See Standing, G. 2011, The Precariat: The New Dangerous Class, London, Bloomsbury.
} 
to open that can enable new forms of public engagement to emerge, encourage dialogues and, moreover, suggest strategies of creative intervention within a range of different communities. ${ }^{18}$

Delineating the cosmopolitan project of art's world-making through the idea of 'precarious ecologies' is a deliberate strategy. As explored above through close attention to the material qualities of the works of Bertola and Brassil, a precarious ecology is not envisaged here as a fixed or bounded entity - it is not a thing, but a process or a state of relations between subjects, objects and their environment. This is significant both in terms of the concept of cosmopolitanism that it underpins and as it reiterates the agency of art as a world-making practice, rather than a representation of the world.

The former point undoes teleology; in envisaging cosmopolitanism as a process of world-making, rather than an end-point, we open the term and the interrelated fields of politics, ethics and aesthetics, to change and development over time. This way of thinking through a cosmopolitan project allows its becoming to remain one of its key features - we never simply arrive. These insights in turn mobilise what philosopher Edward Casey called the 'possibilising' ${ }^{19}$ force of imagining, imagination's potential to provide a locus for the emergence of new and different thought. As a precarious ecology, cosmopolitanism is neither predetermined in content, nor in form; instead, it is understood as a carefullypoised system of relationships that are open to difference, managed through intersubjective generosity and negotiation with others, and constantly changing as the material constraints of the environment evolve. They are risky but worth it.

Art-making as world-making in the stronger sense of materialising these precarious ecologies, does not image the cosmopolitan, but enables imagination to play a critical part in its articulation. Art is thus not a mirror of the world (a representation of the world), but a constituent component in its perpetual remaking, a component whose materiality and affective agency are paramount. Hence, I am not seeking in my exploration of contemporary art to find specific works that are 'about' cosmopolitan ideas, or that paint a picture of a

\footnotetext{
18 I am very aware of art's embeddedness within the systems of global capital and am not suggesting that art provides a utopian space accessible equally to all. However, it would be mistaken to think that all works of contemporary practice reside wholly within, for example, the space of the gallery, when much work is now done in public, cooperative or community spaces and there are many works that seek out new and different audiences, precisely to effect forms of communication that move beyond the 'elite' realms of traditional 'high culture'. On these issues, see for example, Kester, G. H. 2004, Conversation Pieces: Community and Communication in Modern Art, Berkeley, University of California Press.

19 Casey, E. 2000, Imagining: a phenomenological study, [2nd edn], Bloomington, Indiana University Press, pp. 5-12.
} 
cosmopolitan world, but rather to ask how particular works (re)make worlds that open the possibility for the interpellation of cosmopolitan subject-positions and inter-relationships.

The third point in regard to the specificity of the argument being made here in relation to art as a world-making activity and the precarious ecologies of cosmopolitanism takes us back to wonder. Thus far we have explored the experience of wonder as one of the affective states that can be engendered through works of art that make precarious worlds and it has been suggested that these worlds and the subjects who engage with/in them are both changed by their encounter. I want to suggest that the connection with wonder becomes even more prescient when the possibilising force of imagination is placed into this mix, as it is, so strongly, in the case of the aesthetic openness of cosmopolitanism. To take this idea further, and bring the varied strands developed through this text together, it is useful to turn to a final work: Speak Rhymes with Beak, a sound installation piece from 2006 by Johanna Hällsten.

\section{Speaking Enchanting Rhymes}

Speak Rhymes with Beak consists of a three and a half-minute long sound loop, exhibited in gallery spaces accompanied by a log and bird seed. Approaching it, one is invited to light on the log and listen to the sounds of bird calls and human voices intermingled and played through a bell-speaker that focuses the sound, to immerse the listener within its sonic space. The simplicity of the materialsthe log and seed-and the soft surround of the audio experience, entreat us gently to remain with the work as the sound runs its course.

The sound itself consists of three recorded elements: a bird that woke the artist each morning when she stayed at Wuhan University; Professor Chen Wangheng of Wuhan University, speaking the words 'ni hao' (hello), 'saijian' (goodbye) and 'wo ai ni' (I love you) in her dialect, in that order; and ambient sound of birds and noises taken from a garden in Tokyo. These elements were developed into a sonic dialogue by Hällsten, who used digital sound editing to make the morning bird calls 'answer' the human salutations in the sonic setting of the Japanese garden. Slowly, through the subtle manipulation of the sound, the voices of the bird and the woman begin to resonate in tone, pitch, timbre and rhythm, until they are 'speaking' to one another. 


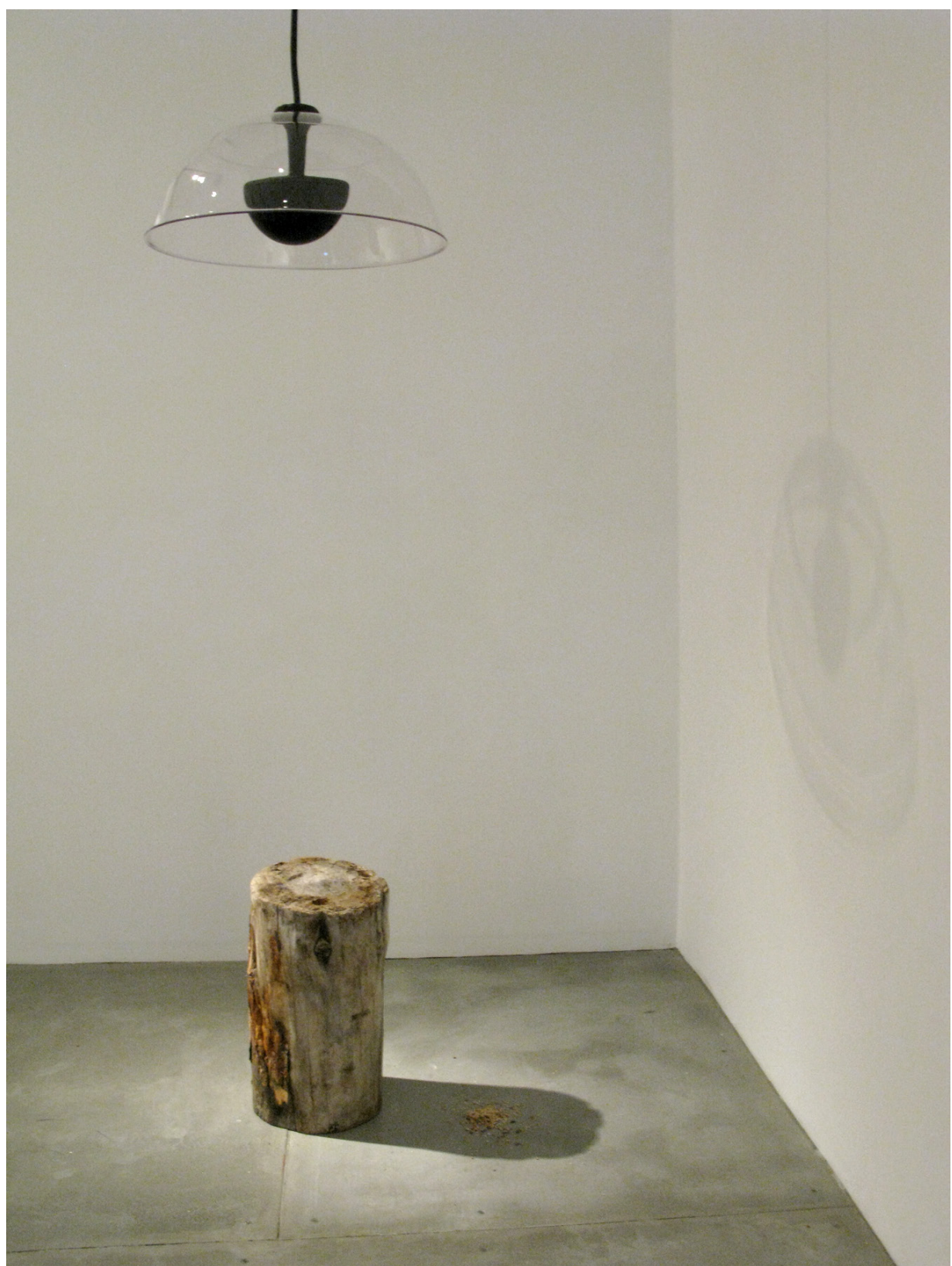

Johanna Hällsten, 2006, Speak Rhymes with Beak, Sound installation, log, bird seed.

Viewed at $<$ http://www.johannahallsten.com/ $>$ 


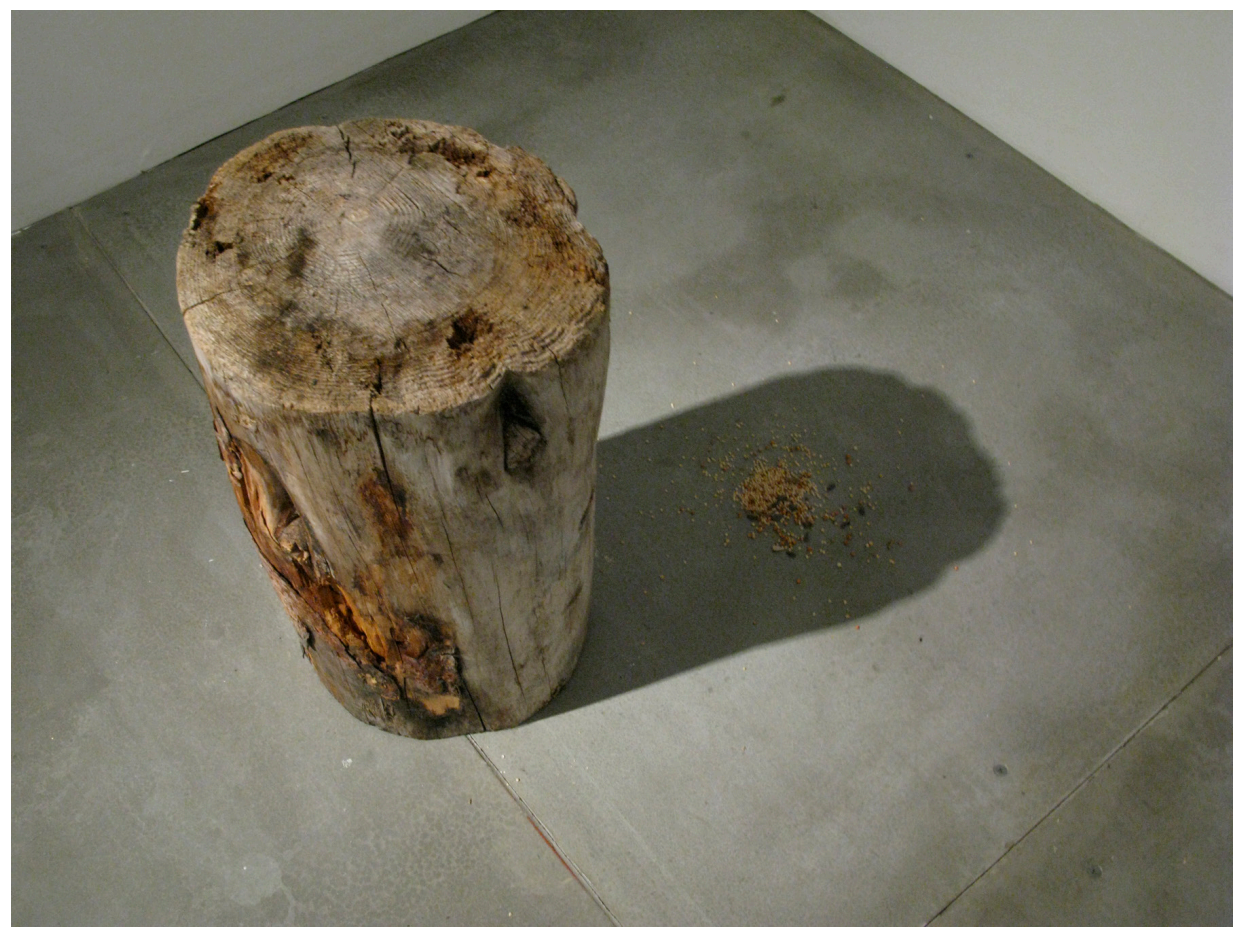

Johanna Hällsten, 2006, Speak Rhymes with Beak (detail), Sound installation, log, bird seed.

Viewed at <http://www.johannahallsten.com/>

Hällsten, a Swedish-born artist living in the UK, frequently works in Asia and a number of her works have explored the problems and opportunities of translation, dialogue and cross-cultural (mis)communication. Derived from her own experiences of the linguistic challenges of working in China, Speak Rhymes with Beak, further extended its translative explorations to human and non-human communication. The woman speaking in the sound piece seeks to 'teach' the bird to speak Chinese; the bird responds, but their interaction is not unidirectional. Instead, it is mutual, as each intones toward and with the other, and each learns to speak a new, shared language that emerges between a Chinese dialect and birdsong. In the end, they intone 'wo ai ni' (I love you) together in their hybrid incantation.

Speak Rhymes with Beak is more directly related to the question of transnational dialogue and exchange than either After the Fact or A Tether of Time, and in that sense, the questions it raises for a cosmopolitan world-making in art might seem more obvious. Clearly, it suggests the possibility of a shared, mutual respect and engagement with difference and the possibility of finding spaces and means through which to communicate productively and generously with 
others with whom we share the world. The work recognises those shared dialogues as mutually-transformative and connective; this is not a model of cultural imposition, where the dominant speaker's language is 'learned' by the other so they can 'communicate'.

But it is not the direct reference to translation or cross-cultural dialogue that makes Hällsten's re-made world so fascinating within a broader discussion of the potential of art to create precarious, cosmopolitan, ecologies. I want to suggest that the affective dimensions of the work reiterate and extend its reach to incorporate the listener within its aural community of exchange. To hear the work requires the listener to settle on the log and be still, to enter into the space that is offered by the work quietly and attentively. The shift in tone in the sound piece is not audible unless we open ourselves to hearing it; it does not shout, it whispers. We are brought close to it, we are entangled with it.

In these phenomena we find again the state of wonder, of the new and extraordinary emerging through the everyday, arresting our attention, opening us to the pleasures of difference and changing us forever. The work is an entreaty, a precarious ecology that invites us to negotiate a new language and be surprised and delighted by the resonant refrain. It enchants.

In her book, The Enchantment of Modern Life: Attachments, Crossings and Ethics, political theorist Jane Bennett argued eloquently for the power of wonder to compel generous ethical agency:

Enchantment entails a state of wonder.... A state of openness to the disturbing, captivating elements in everyday experience.... More specifically, my contention is that enchantment can aid in the project of cultivating a stance of presumptive generosity (i.e., of rendering oneself more open to the surprise of other selves and bodies, and more willing and able to enter into productive assemblages with them). ${ }^{20}$

If the precarious ecologies of cosmopolitanism that are so wonderfully materialised by the world-making agency of contemporary art are to move beyond imagining the new toward ethical action in the world, it is perhaps by cultivating such a stance of generosity. It is not enough to call for an aesthetic of openness, or posit a predetermined and unchanging picture of a cosmopolitan future. To effect the precarious ecologies that enable us to recognise our interdependence with other human and non-human agents and to compel us to enter into connections with them as we share a world, we need to be able to find

20 Bennett, J. 2001, The Enchantment of Modern Life: Attachments, Crossings and Ethics, Princeton, Princeton University Press, p. 131. 
ways to explore and take pleasure in difference without being overwhelmed by it, or seeking to overwhelm others. Such generous intersubjectivity is precarious: risky, dependent upon the will of others and often fleeting.

After the Fact, A Tether of Time, and Speak Rhymes with Beak, each enable us to imaginatively inhabit the world re-made in and through wonder. In each case, as we experience the extraordinary breaking through the fabric of the ordinary, we are changed and our relations within the world are changed as well. The world is dust and it is astounding, the cosmos is everywhere singing, unheard, and it is possible to make strangers friends. We can inhabit the precarious ecologies of cosmopolitanism, but it is risky business. 